\title{
INSTITUIÇÕES DE ENSINO SUPERIOR COM MAIOR CONTRIBUIÇÃO À PÓS- GRADUAÇÃO NO BRASIL - Período entre 1995 e 2014
}

\section{HIGHER EDUCATION INSTITUTIONS WITH GREATER CONTRIBUTION OF POSTGRADUATE IN BRAZIL - Period between 1995 and 2014}

\author{
Caroline Lievore ${ }^{1}$ \\ Priscila Rubbo ${ }^{2}$ \\ Marizete Cechin ${ }^{3}$ \\ Claudia Tania Picinin ${ }^{4}$ \\ Luiz Alberto Pilatti ${ }^{5}$
}

\begin{abstract}
Resumo
O objetivo deste estudo é identificar as Instituições de Ensino Superior (IES) que apresentaram maior contribuição na consolidação da pós-graduação no Brasil, no período entre 1995 e 2014. Os dados foram coletados no Sistema de Informações Georreferenciadas da Capes (GeoCapes). As variáveis utilizadas no estudo foram o "número de programas de pós-graduação", a "distribuição de vínculos docentes", a "distribuição de discentes nas IES", no período entre 1998 e 2014, e a "concessão de bolsas de estudo" por IES, no período entre 1995 e 2014. Os resultados mostram o papel fundamental das universidades públicas, essencialmente as universidades federais, na consolidação da pósgraduação brasileira; confirmam que as universidades com melhores resultados são as que apresentam o maior número de docentes por programa de pós-graduação e revelam que houve queda de $3 \%$ no número de discentes titulados por docente/ano.
\end{abstract}

Palavras-chave Instituições de Ensino Superior. Pós-Graduação. Produção Científica.

\begin{abstract}
The aim of this study is to identify Higher Education Institutions (HEI) had greater contribution in postgraduate studies consolidation in Brazil, between 1995 and 2014. The data were collected in the Georeferenced Information System Capes (GeoCapes). The variables used in the study were the "number of graduate programs," the "distribution of teachers bonds", the "distribution of students in HEIs", between 1998 and 2014, and the "granting of scholarships" by HEIs in the period between 1995 and 2014. The results show the key role of public universities, mainly the federal universities, in the consolidation of Brazilian postgraduate; confirm that universities with the best results are those with the highest number of teachers for postgraduate program and show that there was a decrease of $3 \%$ in the number of students per certificated teacher/year.

Key words Higher Education Institutions. Postgraduate Studies. Scientific Production.
\end{abstract}

\footnotetext{
${ }^{1}$ Doutoranda em Ensino de Ciência e Tecnologia pela Universidade Tecnológica do Paraná (UFTPR) email: carolievore1@gmail.com

${ }^{2}$ Doutoranda em Engenharia de Produção pela Universidade Tecnológica do Paraná (UTFPR).

Email: priscilarubbo@utfpr.edu.br

${ }^{3}$ Doutoranda em Ensino de Ciência e Tecnologia pela Universidade Tecnológica do Paraná (UFTPR).

4 - Doutora em Administração, Professora do Programa de Pós-Graduação em Engenharia de Produção da Universidade Tecnológica Federal do Paraná (UTFPR).

${ }^{5}$ Doutor em Educação Física, Professor do Programa de Pós-Graduação em Ensino de Ciência e Tecnologia da Universidade Tecnológica Federal do Paraná (UTFPR) e Reitor da UTFPR.
} 


\section{INTRODUÇÃO}

O Sistema de Pós-graduação brasileiro ganhou destaque no ranking mundial de produção científica e algumas Instituições de Ensino Superior (IES) se apresentaram fundamentais para o desenvolvimento da pós-graduação, colaborando diretamente com o crescimento da ciência e com o aumento das publicações científicas nacionais.

Meis et al. (2007) citam que existe uma relação estreita entre o número de mestres e de doutores formados e o número de publicações científicas em revistas internacionais, indicando que a expansão da pós-graduação nas IES, ao longo dos anos, contribuiu diretamente no crescimento da ciência brasileira.

A produção científica do Brasil concentra-se basicamente nos cursos de pós-graduação e nas universidades públicas. A criação de leis de apoio à ciência e à tecnologia vem favorecendo o crescimento contínuo da pesquisa científica acadêmica. No início dos anos 1990, a Capes implementou o sistema de avaliação dos programas de pós-graduação que garantiriam seu desenvolvimento e sua inserção no contexto mundial de produção científica (FIORINI, 2015). Contudo, o crescimento de todo o sistema está relacionado diretamente com o desenvolvimento e com a implementação das ações propostas nos Planos Nacionais de PósGraduação (PNPG), criados em meados da década de 1970 e que funcionam como direcionadores e alavancas da pós-graduação (BRASIL, 2010; ALMEIDA; GUIMARÃES, 2013). Entre o I PNPG (1975-1979) e o VI PNPG (2011-2020), a Capes buscou organizar seus processos, métodos e avaliações, elevando a qualidade do sistema nacional de pósgraduação a um patamar competitivo.

O presente estudo tem por objetivo identificar as Instituições de Ensino Superior que apresentaram maior contribuição na consolidação da pós-graduação brasileira, no período entre 1995 e 2014, através dos dados disponíveis no Sistema de Informações Georreferenciadas da Capes (GeoCapes). Com a perspectiva de entender o papel das IES que sustentam o sistema de pós-graduação nacional, esta pesquisa justifica-se por expor de forma sistemática o quanto cada instituição se desenvolveu no período entre 1995 e 2014 com relação às variáveis propostas. O crescimento e a consolidação da pós-graduação geram produtos diretos, como a pesquisa científica e a produção de conhecimentos, contribuindo diretamente no desenvolvimento social da nação.

\section{O papel das IES e da Pós-graduação no contexto científico brasileiro}


A evolução da ciência brasileira possui relação direta com o sistema de pós-graduação nacional. Neste sentido, a produção científica realizada através dos programas de pósgraduação é fundamental para o desenvolvimento científico e tecnológico do país, tanto pelas pesquisas realizadas quanto pelo papel da pós-graduação na formação de pesquisadores (GUIMARÃES, 2004; MEIS et al., 2007). Os avanços da pós-graduação brasileira são observados tendo em vista o crescimento quantitativo das IES e dos programas de mestrado e de doutorado, bem como o crescimento da produção científica nacional.

No Brasil a ciência básica é sustentada quase inteiramente em universidades ou institutos de pesquisa (SOUZA, 2015). De acordo com Leite (2014), nos últimos 20 anos, o Brasil cresceu onze posições no ranking dos países mais produtivos em ciência, conforme evidenciado na Tabela 1. Conforme levantamento feito pela empresa Thomson Reuters, que detém a maior base de dados científicos do mundo, entre 1993 e 2013, o Brasil cresceu 700\%, chegando a $13^{\circ}$ posição no ranking mundial.

\begin{tabular}{|l|l|l|l|}
\hline \multicolumn{1}{|c|}{} & EUA & 383.745 \\
\cline { 2 - 3 } & 2 & Inglaterra & 74.773 \\
\hline 3 & Japão & 64.977 \\
\hline 4 & Alemanha & 61.333 \\
\hline 5 & França & 48.061 \\
\hline 6 & Canadá & 46.371 \\
\hline 7 & Itália & 29.334 \\
\hline 8 & Rússia & 27.291 \\
\hline 9 & Austrália & 22.034 \\
\hline 10 & Holanda & 20.243 \\
\hline 11 & Espanha & 17.005 \\
\hline 12 & Índia & 16.826 \\
\hline 13 & Suécia & 14.099 \\
\hline 14 & Suíça & 13.061 \\
\hline 15 & China & $\mathbf{1 2 . 5 8 6}$ \\
\hline 16 & Escócia & 10.430 \\
\hline 17 & Israel & 9.677 \\
\hline 18 & Bélgica & 9.055 \\
\hline 19 & Dinamarca & 7.139 \\
\hline 20 & Polônia & 7.111 \\
\hline 21 & Finlândia & 6.113 \\
\hline 22 & Taiwan & 5.858 \\
\hline 23 & Áustria & 5.762 \\
\hline 24 & Brasil & $\mathbf{5 . 4 5 7}$ \\
\hline 25 & Noruega & 4.664 \\
\hline
\end{tabular}

\begin{tabular}{|l|l|l|l|}
\hline & 1 & EUA & 429.556 \\
\hline 2 & China & $\mathbf{2 8 8 . 4 2 4}$ \\
\hline 3 & Alemanha & 114.316 \\
\hline 4 & Inglaterra & 108.311 \\
\hline 5 & Japão & 90.678 \\
\hline 6 & França & 78.979 \\
\hline 7 & Canadá & 70.471 \\
\hline 8 & Itália & 70.216 \\
\hline 9 & Índia & 62.282 \\
\hline 10 & Espanha & 60.230 \\
\hline 11 & Austrália & 59.913 \\
\hline 12 & Coreia do Sul & $\mathbf{5 6 . 2 6 2}$ \\
\hline $\mathbf{7}$ & Brasil & $\mathbf{4 2 . 9 3 1}$ \\
\hline 13 & Holanda & 40.951 \\
\hline 14 & 32.956 \\
\hline 15 & Taiwan & 32.263 \\
\hline 16 & Rússia & 39.801 \\
\hline 17 & Suíça & 29.765 \\
\hline 18 & Turquia & 28.765 \\
\hline 19 & Irã & 28.197 \\
\hline 20 & Polônia & 27.185 \\
\hline 21 & Suécia & 26.725 \\
\hline 22 & Bélgica & 22.730 \\
\hline 23 & Dinamarca & 17.020 \\
\hline 24 & Escócia & 16.089 \\
\hline 25 & Áustria & 15.679 \\
\hline
\end{tabular}

Tabela 1: Ranking dos 25 países como maior produção científica de 1993 e 2013 Fonte: Adaptado de Leite (2014) 
A China aumentou sua produção em $2.292 \%$, subindo da $15^{\circ}$ posição em 1993 para a $2^{\circ}$ posição em 2013. Outro país que se destaca é a Coreia do Sul, que em 1993 não aparecia nesse ranking e em 2013 aparece na $12^{\circ}$ posição. Os EUA, mesmo com um ritmo de crescimento menor que a China (112\%), manteve-se no topo do ranking.

A pesquisa brasileira evoluiu tanto em quantidade como em qualidade, visto que o crescimento de publicações científicas do país é superior à média mundial de países como México, Argentina, Japão, Reino Unido, Alemanha e EUA. Nas últimas três décadas, a produção científica nacional atingiu uma taxa de crescimento média de $10,7 \%$ ao ano. O crescimento possibilitou que a nação fizesse parte do grupo dos 26 países com contribuição individual igual ou superior a $1 \%$ no ranking de produção científica mundial (LEITE, 2014; ALMEIDA; GUIMARÃES, 2013).

Almeida e Guimarães (2013) calcularam o fator de impacto para os 26 países que apresentaram produção científica indexada à base de dados Thomson Reuters igual ou superior a $1 \%$, a fim de medir a qualidade do que é publicado. Com um fator de impacto de 3,03, ou seja, muito aquém das expectativas, o sistema de pós-graduação brasileiro mostra suas fragilidades. Países com produção científica menor que o Brasil, como a Suíça (1,72\% da produção científica mundial), a Bélgica (1,41\%), a Escócia $(1,07 \%)$ e a Dinamarca $(0,97 \%)$, possuem fatores de impacto maiores: 6,96 (Suíça), 6,77 (Bélgica), 7,48 (Escócia) e 7,64 (Dinamarca).

Dados da Thomson Reuters mostram que no Brasil a área do conhecimento que mais produziu artigos foi a Medicina Clínica. No período entre 2008 a 2012, foram produzidos quase 35 mil artigos. Em segundo lugar está a área de Ciência de Vegetais e Animais, com 19,5 mil artigos no mesmo período. Ciências Agrárias aparecem em terceiro, com uma produção de 13,5 mil artigos entre 2008 e 2012. Entretanto, o maior crescimento foi visto nas Ciências Sociais e gerais, que saltaram de 1,5 mil entre 2003 e 2007 para 9,8 mil entre 2008 e 2012 (LEITE, 2014). A produção científica de 2012 por área de conhecimento no Brasil está apresentada no Gráfico 1. 


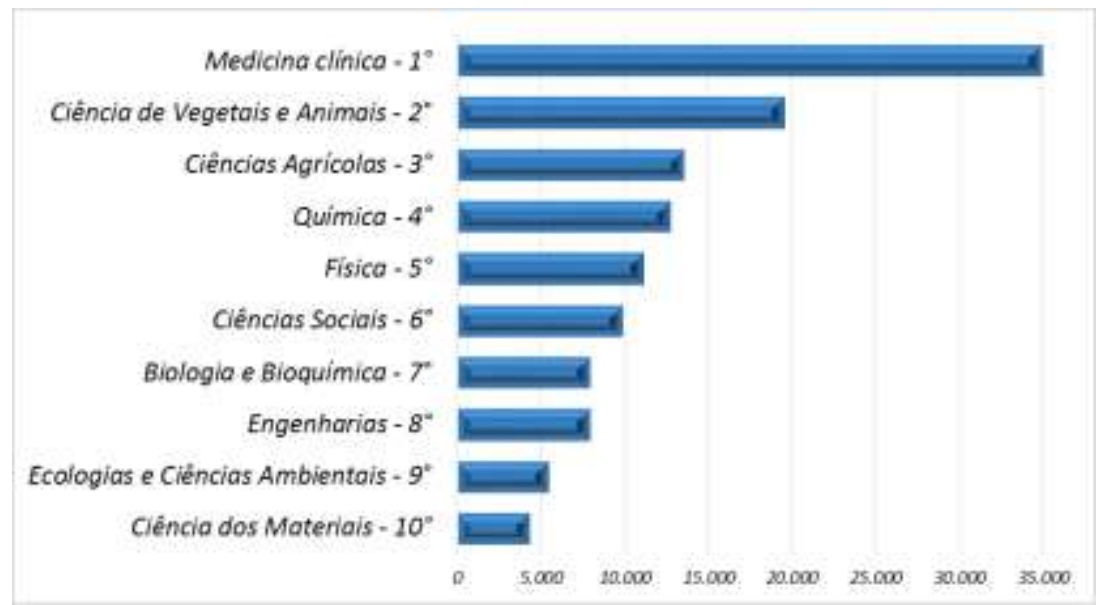

Gráfico 1 - Ranking do número de estudos por área do conhecimento no Brasil em 2012 Fonte: Thomson Reuters apud Leite (2014)

Um estudo feito por -Almeida e Guimarães (2013) mostrou que o desempenho da ciência brasileira ainda carece da uniformidade observada em países mais desenvolvidos. Em muitas áreas, a qualificação dos recursos humanos não está consolidada e o crescimento dos programas de pós-graduação é modesto. Por essa razão, o crescimento científico foi subscrito por campos mais consolidados, como a Física, a Medicina, a Química e as Ciências Biomédicas, que juntas representam cerca de $70 \%$ da produção nacional de conhecimento.

Conforme a Academia Brasileira de Ciências, o relatório da Royal Society, que analisa as publicações científicas no mundo, pela primeira vez, uma cidade sul-americana entrou no ranking das 20 cidades mais produtivas cientificamente. São Paulo foi citada no relatório como um centro de pesquisa de grandeza semelhante a Nova York, Paris, Londres, Pequim e Tóquio (CRUZ e BEIRÃO, 2011). A capital paulista é responsável por uma em cada cinco pesquisas científicas do país, sendo que em 2014, somente a pós-graduação da USP formou 2.669 doutores e 3.592 mestres (GEOCAPES, 2016). Os números são equivalentes a $16 \%$ do total formado no país e são consequências de décadas de investimentos no setor da educação da instituição.

No período entre 2000 e 2009, Almeida e Guimarães (2013) listaram as IES que apresentaram maior número de publicações com autores brasileiros. Os mais de 5 mil artigos de revisão com temas científicos foram produzidos por 27.096 autores e publicados em 1.294 
periódicos. O estudo mostra que 5.077 (95\%) dos artigos foram produzidos por 20 instituições e apenas uma não era pública.

Apesar dos avanços conquistados pelo país na área da educação, a Organização para a Cooperação e Desenvolvimento Econômico (OCDE) divulgou o Relatório Education at a Gance 2014, elaborado pela própria OCDE, que desenvolve e analisa os indicadores comparáveis a nível internacional. Os dados do relatório podem ser usados para auxiliar os governos na construção de sistemas de ensino eficazes.

O Relatório de 2014 mostrou que os investimentos no setor educacional brasileiro ainda estão aquém do ideal para a evolução da ciência nacional e distante da média das nações mais desenvolvidas. Participaram da pesquisa 35 países. Um dos indicadores avaliados referese aos investimentos financeiros por aluno (ensinos fundamental, médio e superior), em que se constatou que o gasto médio anual por estudante brasileiro em 2011 era de US\$ 3.066, colocando o Brasil em penúltimo lugar, superando apenas a Indonésia, com seus US\$ 625. No entanto, entre 2005 e 2011, o Brasil incrementou em 50\% os investimentos por aluno (OCDE, 2014).

Em 2011, os investimentos com estudantes brasileiros foram inferiores aos investimentos de países com renda similar ao Brasil, como o México (US\$ 3.286), Turquia (US\$ 3.240) e Chile (US\$ 5.522). A média de investimento por aluno dos países que participam da OECD (Brasil não faz parte desse grupo) foi de US\$ 9.487. No topo da lista está a Suíça com US\$ 16.090, seguida pelos EUA com US\$ 15.345 e a Noruega, com um gasto anual de US\$14.288 por aluno (OCDE, 2014).

O relatório da OCDE também aponta que os investimentos em educação, que são proporcionais ao PIB, passaram de 3,5\% em 2000 para 5,9\% em 2011, percentual muito próximo da média dos países membros da OCDE, em que o número chega a 6,1\% do PIB (OCDE, 2014).

Uma pesquisa feita em 2011 pelo Instituto de Pesquisa Econômica Aplicada (IPEA) sobre gastos com Políticas Públicas, analisando os multiplicadores do PIB, mostrou que o gasto social em educação tem o maior multiplicador dentre os agregados que se investigou (saúde, construção civil, exportações, entre outros). Isso significa que, ao se gastar $\mathrm{R} \$ 1,00$ em educação pública, o PIB aumentará em R \$ 1,85, pelo simples processo de multiplicação da renda que a atividade propicia (IPEA, 2011).

No Brasil, as IES são avaliadas através de alguns rankings, por exemplo, o Ranking Universitário Folha (RUF), realizado anualmente pelo Jornal Folha de São Paulo, que avalia 
as universidades desde 2012. Na edição de 2015 foram disponibilizados dois produtos principais: o ranking de universidades e o de cursos. No ranking de universidades foram classificadas 192 universidades brasileiras, públicas e privadas, a partir de cinco indicadores: (1) Pesquisa, (2) Internacionalização, (3) Inovação, (4) Ensino, e (5) Mercado. De todos os quesitos avaliados, dois estão diretamente vinculados aos programas de pós-graduação: pesquisa e internacionalização. Na edição de 2015, das dez IES que melhor pontuaram no ranking, seis são universidades Federais e quatro, Estaduais.

A Universidade de São Paulo (USP) ocupa o primeiro lugar em três dos cinco quesitos de avaliação realizados pelo RUF. No indicador que avalia características referentes ao Ensino, a Universidade Federal de Minas Gerais (UFMG) aparece em primeiro lugar. Sobre o indicador Internacionalização, a Fundação Universidade Federal do Abc (UFABC), que se classificou na $42^{\circ}$ posição geral do RUF, está em primeiro lugar, por ser a IES com maior número de citações internacionais por docente. Entre as dez IES que apresentaram melhor classificação no ranking, cinco estão localizadas na região Sudeste, três na região Sul, uma no Centro-Oeste e uma no Nordeste.

Além do RUF, há rankings internacionais, como o QS World University Ranking, o ranking Academic Ranking of World Universities (ARWU), o Times Higher Education World University Rankings (THE), entre outros. Dos rankings internacionais, pinçando apenas o QS, que avalia, desde 2004, as 800 melhores IES, observa-se, na edição de 2015, que a USP, única IES brasileira que aparecia entre as 200 melhores universidades do mundo, caiu de posição pelo segundo ano consecutivo, distanciando-se de sua melhor posição, a $127^{\mathrm{a}}$ colocação, alcançada na edição de 2013 do ranking.

A última lista divulgada (setembro/2015) pela QS traz o Instituto de Tecnologia de Massachussets (MIT) no primeiro lugar. Entre as 200 melhores universidades do mundo, duas brasileiras são referenciadas: a USP, na $143^{\mathrm{a}}$ posição, e pela primeira vez, a Universidade Estadual de Campinas (UNICAMP), no $195^{\circ}$ lugar. A UNICAMP vem mostrando seu crescimento nos últimos dois anos, sendo que em 2013, ocupava $215^{\text {a }}$ colocação e em 2014 atingiu a 206 ${ }^{\text {a }}$ posição. Em 2015, a melhor universidade latino-americana, segundo o QS, foi a Universidade de Buenos Aires (UBA), que ocupa a 124 colocação.

Moustafá (2014) trata os rankings como efeitos desastrosos da onda fator de impacto, visto que a classificação é quase que sempre baseada em critérios subjetivos e tendenciosos por compararem instituições heterogêneas, diferentes em quase tudo, qualificação pessoal, 
número de discentes, docentes e infraestrutura. Para esse autor, a comparação não é válida a partir de um ponto de vista científico porque compara estruturas incomparáveis.

\section{METODOLOGIA}

O corpus documental foi constituído através do site da Coordenação de Aperfeiçoamento e Pessoal de Nível Superior (CAPES), que possui um sistema de indicadores da pós-graduação no Brasil chamado de GeoCapes.

O GeoCapes é uma ferramenta de dados de georreferência capaz de referenciar dados e informações dos índices gerenciados pela Capes no Brasil e no exterior, de acordo com a localização geográfica. Dentre os indicadores disponibilizados pela GeoCapes, foram analisadas as seguintes variáveis:

\begin{tabular}{|c|c|}
\hline VARIÁVEIS & Período \\
\hline 1. IES com maior número de programas de pós-graduação & De 1998 a 2014 \\
\hline 2. IES com maior número de vínculos docentes & De 2004 a 2014 \\
\hline 3. IES com maior número de discentes titulados & De 1998 a 2014 \\
\hline 4. IES com maior número de concessão de bolsas de estudo & De 1995 a 2014 \\
\hline
\end{tabular}

Para cada variável foram consideradas somente as dez IES que mais se destacaram em 2014. Metodologicamente, o estudo é uma análise descritiva e exploratória dos dados, sendo tratados estatisticamente, constatando-se as médias, a representatividade e a evolução para cada variável, relacionando-as ou as confrontando.

Os dados foram coletados no período entre novembro de 2015 e abril de 2016.

As variáveis permitem analisar como as IES contribuem para o crescimento da pósgraduação brasileira em função dos indicadores apresentados pela base de dados GeoCapes, a fim de alcançar o objetivo proposto neste estudo.

A variável número de docentes vinculados ao sistema de pós-graduação foi analisada a partir de 2004

\section{RESULTADOS}

IES com maior número de programas de pós-graduação no país 
Segundo dados da Capes (GEOCAPES, 2016), em 2014 o Brasil contava com 379 IES, responsáveis por 3.729 programas de pós-graduação stricto-senso, reconhecidos pelo MEC (média de 9,7 programas por IES). Das instituições, 203 (53,56\%) possuem até três programas de pós-graduação, 74 IES (19,53\%) possuem entre quatro e sete programas de pósgraduação e 102 IES (26,71\%) possuem entre oito e 50 programas de pós-graduação reconhecidos.

Na Tabela 2, as dez IES que apresentaram o maior número de programas de pósgraduação do país entre 1998 e 2014.

\begin{tabular}{|l|r|r|r|r|r|r|r|r|r|r|r|r|r|r|r|r|r|}
\hline \multicolumn{1}{|c|}{ IES } & $\mathbf{1 9 9 8}$ & $\mathbf{1 9 9 9}$ & $\mathbf{2 0 0 0}$ & $\mathbf{2 0 0 1}$ & $\mathbf{2 0 0 2}$ & $\mathbf{2 0 0 3}$ & $\mathbf{2 0 0 4}$ & $\mathbf{2 0 0 5}$ & $\mathbf{2 0 0 6}$ & $\mathbf{2 0 0 7}$ & $\mathbf{2 0 0 8}$ & $\mathbf{2 0 0 9}$ & $\mathbf{2 0 1 0}$ & $\mathbf{2 0 1 1}$ & $\mathbf{2 0 1 2}$ & $\mathbf{2 0 1 3}$ & $\mathbf{2 0 1 4}$ \\
\hline USP & 205 & 211 & 211 & 216 & 217 & 220 & 215 & 220 & 223 & 221 & 225 & 227 & 224 & 224 & 230 & 243 & 251 \\
\hline UNESP & 74 & 83 & 90 & 84 & 95 & 97 & 98 & 100 & 104 & 102 & 107 & 109 & 111 & 112 & 114 & 121 & 128 \\
\hline UFRJ & 80 & 84 & 83 & 82 & 83 & 84 & 81 & 82 & 85 & 82 & 82 & 91 & 93 & 97 & 99 & 102 & 106 \\
\hline UNB & 41 & 42 & 46 & 44 & 44 & 46 & 52 & 52 & 59 & 60 & 64 & 66 & 68 & 77 & 84 & 87 & 87 \\
\hline UFRGS & 59 & 57 & 63 & 64 & 66 & 66 & 69 & 73 & 75 & 78 & 78 & 79 & 78 & 79 & 82 & 81 & 83 \\
\hline UFMG & 54 & 55 & 56 & 48 & 58 & 61 & 61 & 62 & 64 & 67 & 67 & 69 & 68 & 69 & 70 & 72 & 76 \\
\hline UFBA & 28 & 29 & 32 & 33 & 36 & 37 & 37 & 40 & 45 & 51 & 53 & 57 & 62 & 69 & 71 & 73 & 75 \\
\hline UFPE & 43 & 43 & 42 & 55 & 49 & 51 & 55 & 56 & 58 & 56 & 58 & 63 & 66 & 69 & 72 & 72 & 72 \\
\hline UFPR & 30 & 34 & 35 & 38 & 40 & 43 & 45 & 47 & 50 & 51 & 52 & 56 & 60 & 64 & 66 & 68 & 70 \\
\hline UFF & 32 & 34 & 36 & 35 & 36 & 40 & 40 & 40 & 40 & 41 & 42 & 47 & 47 & 55 & 60 & 67 & 67 \\
\hline
\end{tabular}

Tabela 2 - As dez IES com maior número de programas de pós-graduação no período entre 1998 e 2014 Fonte: Geocapes (2016)

As universidades públicas destacam-se na quantidade de programas de pós-graduação. Souza (2015) ressalta que apesar de o Brasil revelar um crescimento acentuado do ensino superior privado, os resultados apontam que há uma excessiva concentração da produção científica nas universidades públicas. Até o final do século XX, as IES públicas vinham crescendo fortemente na pós-graduação, o que ajuda a desconstruir o conceito de que o setor público é ineficiente. Contudo, evidencia-se que há uma paralisia ou inépcia das universidades privadas em fazer pesquisa. O cenário é indício da necessidade de políticas governamentais que incentivem as instituições privadas a implementar cursos de pósgraduação ou a fortalecê-los, como uma das formas de alavancar o Brasil nas pesquisas científicas.

Apesar de sete das dez IES com maior número de cursos de pós-graduação serem instituições federais, a USP destaca-se como a universidade brasileira com o maior número de programas e a única com programas em todas as áreas do conhecimento. Em 2015, a USP 
ocupou o primeiro lugar no RUF, quanto ao indicador Pesquisa e Inovação, confirmando a estreita ligação existente entre a pós-graduação e o crescimento científico, visto que é também a universidade com maior número de publicações científicas no Brasil. Contudo, quanto ao fator Internacionalização, a mesma ocupa o quinto lugar.

Percebe-se uma correlação entre o Programa Federal Reuni, que incentiva e promove reestruturação e expansão das universidades federais, com o crescimento dos cursos de pósgraduação no país. Entre 1998 e 2003, ano de criação do Reuni, o número de programas de pós-graduação no país nas dez principais IES cresceram 13,6\%. Após o Reuni, entre 2004 e 2014, o crescimento foi de 35,3\%, puxado principalmente por instituições federais como a Universidade Federal da Bahia (UFBA), Universidade Federal do Paraná (UFPR) e Universidade Federal Fluminense (UFF), que no período avaliado, aumentaram o número de pós-graduações em mais de $100 \%$.

Segundo Cirani et al. (2015), a ampliação da pós-graduação não pode ser creditada somente ao crescimento dos cursos de pós-graduação. Há que se preocupar cada vez mais com a qualidade dos programas e com o incentivo para a pesquisa científica no país. Entretanto, observa-se que das dez universidades com maior número de programas de pósgraduação, apenas duas (UFBA e UFF) não estão classificadas entre as dez melhores no Ranking da Folha, inferindo que as IES estão preocupadas com a qualidade dos programas de pós-graduação.

Para que o Brasil continue crescendo em ciência e tecnologia é fundamental a continuidade de políticas públicas de incentivos à ampliação de programas de pós-graduação sem perdas para a qualidade do ensino e da pesquisa. Além disso, há que se criar meios de incentivar o desenvolvimento da pós-graduação no setor privado.

\section{IES com maior número de vínculos docentes no país}

O número de vínculos docentes retrata o número de professores que estão atuantes em programas de pós-graduação. Cabe salientar que um único docente pode estar vinculado em mais de um programa de pós-graduação ao mesmo tempo, ou seja, o número de vínculos não representa o número de contratações.

O número de docentes vinculados à pós-graduação é apresentado no GeoCapes em dois períodos: o primeiro findado em 2003 (em que os docentes eram classificados como NRD3, NRD5 e NRD6) e o segundo, após 2004 (quando os docentes passaram a ser classificados como permanentes, colaboradores e visitantes). Nessa pesquisa, optou-se por 
analisar o número de vínculos a partir de 2004, com os docentes nominados de permanentes, colaboradores ou visitantes.

Entre 2004 e 2014, o número de vínculos cresceu 106,86\%. Observa-se que o número de docentes permanentes em 2014 foi $311 \%$ superior ao número de professores enquadrados como colaboradores, em uma relação de 66.330 permanentes para 16.140 professores colaboradores. Já o número de docentes visitantes foi de apenas 1.460, representando somente $1,8 \%$ do total. A alta concentração de docentes com vínculo permanente denota que o quadro efetivo do sistema de pós-graduação manteve-se fortalecido e capaz de atender todas as exigências impostas pela Capes em seu método de avaliação.

Na Tabela 3, estratificou-se as dez IES com o maior número de vínculos docentes entre 2004 e 2014.

\begin{tabular}{|l|r|r|r|r|r|r|r|r|r|r|r|}
\hline IES & $\mathbf{2 0 0 4}$ & $\mathbf{2 0 0 5}$ & $\mathbf{2 0 0 6}$ & $\mathbf{2 0 0 7}$ & $\mathbf{2 0 0 8}$ & $\mathbf{2 0 0 9}$ & $\mathbf{2 0 1 0}$ & $\mathbf{2 0 1 1}$ & $\mathbf{2 0 1 2}$ & $\mathbf{2 0 1 3}$ & $\mathbf{2 0 1 4}$ \\
\hline USP & 6242 & 6329 & 6338 & 6451 & 6572 & 6798 & 6722 & 7027 & 7315 & 7687 & 7905 \\
\hline UNESP & 2243 & 2332 & 2364 & 2396 & 2481 & 2532 & 2601 & 2714 & 2774 & 3123 & 3291 \\
\hline UFRJ & 1995 & 2066 & 2132 & 2193 & 2238 & 2418 & 2515 & 2644 & 2727 & 2922 & 3045 \\
\hline UNICAMP & 2086 & 2118 & 2208 & 2148 & 2197 & 2273 & 2154 & 2345 & 2443 & 2628 & 2662 \\
\hline UFRGS & 1654 & 1742 & 1826 & 1908 & 1965 & 2033 & 2052 & 2094 & 2191 & 2303 & 2432 \\
\hline UFMG & 1444 & 1507 & 1570 & 1633 & 1633 & 1710 & 1803 & 1890 & 1956 & 2153 & 2274 \\
\hline UNB & 1063 & 1154 & 1293 & 1269 & 1352 & 1453 & 1011 & 1678 & 1157 & 2153 & 2220 \\
\hline UFRN & 534 & 622 & 690 & 738 & 777 & 888 & 1011 & 1119 & 1157 & 1701 & 1931 \\
\hline UFBA & 847 & 931 & 1067 & 1211 & 1226 & 1356 & 1454 & 1602 & 1691 & 1781 & 1912 \\
\hline UFSC & 1148 & 1167 & 1211 & 1261 & 1320 & 1383 & 1456 & 1549 & 1889 & 1669 & 1711 \\
\hline
\end{tabular}

Tabela 3 - IES com maior número de docentes vinculados à pós-graduação de 2004 a 2014 Fonte: Geocapes (2016)

A USP, a UNESP e a UFRJ possuem o maior número de programas, consequentemente, apresentaram os primeiros lugares quanto a quantidade de docentes com vínculos aos programas de pós-graduação. As instituições que mais tiveram docentes vinculados no período analisado, representando mais que $100 \%$ de crescimento, foram a UNB, a Universidade Federal do Rio Grande do Norte (UFRN) e a UFBA.

O crescimento de vínculos docentes da UNB e da UFBA justifica-se pelo fato de que essas IES dobraram o número de programas de pós-graduação. No entanto, em caminho inverso, a UFF e a UFPR que também dobraram o número de programas no período avaliado, não tiveram o mesmo crescimento de vínculos docentes, as quais aumentaram em 57,37\% 
(UFF) e 40,07\% (UFPR), não figurando entre as dez instituições com o maior número de docentes.

O país encerrou 2014 com um total de 84.242 vínculos docentes em programas de pósgraduação, o que representa uma média de 22 docentes vinculados por programa de pósgraduação. A correlação entre o número de programas e o número de docentes revela que, entre as instituições avaliadas, a USP, a UNICAMP e a UFRJ são as universidades com melhor produtividade científica, segundo Almeida e Guimarães (2013), e com os melhores índices de qualidade, segundo o RUF, as três IES possuem quantidade de docentes por programa de 31,5; 36 e 28,7, respectivamente, valores acima da média geral. Infere-se com isso, que a qualidade do programa pode estar diretamente relacionada à quantidade de docentes disponíveis para orientação e condução de pesquisas científicas.

Instituições como a UFMG, a UFRGS e a UFRN, com média de vínculos docentes semelhantes às citadas anteriormente, próximo a 29 docentes por programa, apresentam oportunidades de aumento quantitativo tanto de programas de pós-graduação como de aumento da produção científica por docente vinculado, trazendo efeito positivo no desenvolvimento da instituição.

\section{IES com maior número de discentes no país}

Entre 1998 e 2014, o sistema de pós-graduação apresentou crescimento de 205,43\% no total de alunos matriculados e 311,74\% de alunos titulados nos programas de pós-graduação no país. Na tabela 5, observa-se as IES com maior número de discentes titulados em programas de pós-graduação no Brasil entre 1998 e 2014.

\begin{tabular}{|l|r|r|r|r|r|r|r|r|r|r|r|r|r|r|r|r|r|}
\hline \multicolumn{1}{|c|}{ IES } & $\mathbf{1 9 9 8}$ & $\mathbf{1 9 9 9}$ & $\mathbf{2 0 0 0}$ & $\mathbf{2 0 0 1}$ & $\mathbf{2 0 0 2}$ & $\mathbf{2 0 0 3}$ & $\mathbf{2 0 0 4}$ & $\mathbf{2 0 0 5}$ & $\mathbf{2 0 0 6}$ & $\mathbf{2 0 0 7}$ & $\mathbf{2 0 0 8}$ & $\mathbf{2 0 0 9}$ & $\mathbf{2 0 1 0}$ & $\mathbf{2 0 1 1}$ & $\mathbf{2 0 1 2}$ & $\mathbf{2 0 1 3}$ & $\mathbf{2 0 1 4}$ \\
\hline USP & 3495 & 4000 & 4283 & 4517 & 5380 & 5540 & 4852 & 5469 & 5418 & 5470 & 5710 & 5786 & 5834 & 5634 & 6108 & 6228 & 6261 \\
\hline UNESP & 882 & 1065 & 1330 & 1635 & 1791 & 2068 & 1757 & 2023 & 1944 & 2072 & 2266 & 2396 & 2400 & 2582 & 2596 & 2800 & 2965 \\
\hline UFRJ & 1356 & 1600 & 1661 & 1731 & 1871 & 2003 & 2090 & 2225 & 2207 & 2158 & 2296 & 2202 & 2246 & 2290 & 2437 & 2567 & 2466 \\
\hline UFRGS & 774 & 929 & 1165 & 1300 & 1540 & 1664 & 1331 & 1657 & 1632 & 1719 & 1706 & 1984 & 1862 & 2068 & 2380 & 2377 & 2324 \\
\hline UFMG & 648 & 750 & 938 & 1065 & 1200 & 1338 & 1440 & 1470 & 1505 & 1654 & 1603 & 1697 & 1729 & 1865 & 1950 & 2022 & 2013 \\
\hline UNICAMP & 1219 & 1261 & 1358 & 1705 & 1738 & 1880 & 1924 & 1901 & 1867 & 1835 & 1802 & 1952 & 1837 & 1950 & 1947 & 2048 & 2196 \\
\hline UNB & 332 & 530 & 608 & 623 & 859 & 982 & 917 & 1033 & 1171 & 1120 & 1330 & 1298 & 1157 & 1304 & 1421 & 1899 & 1724 \\
\hline UFPE & 300 & 420 & 549 & 584 & 807 & 989 & 842 & 857 & 1045 & 941 & 1170 & 1309 & 1285 & 1502 & 1565 & 1611 & 1598 \\
\hline
\end{tabular}




\begin{tabular}{|l|r|r|r|r|r|r|r|r|r|r|r|r|r|r|r|r|r|}
\hline UFSC & 762 & 925 & 1260 & 1098 & 1267 & 1196 & 1047 & 1266 & 1214 & 1271 & 1303 & 1296 & 1369 & 1452 & 1555 & 1687 & 1596 \\
\hline UFPR & 262 & 368 & 484 & 559 & 652 & 715 & 808 & 895 & 924 & 881 & 974 & 1018 & 1024 & 1238 & 1211 & 1431 & 1485 \\
\hline
\end{tabular}

Tabela 4 - IES com maior número de discentes titulados na pós-graduação de 1998 a 2014 Fonte: Geocapes (2016)

Dentre as instituições presentes na Tabela 4, as que mais elevaram o número de discentes no período estudado foi a UNB, com um aumento de 419,28\%, a Universidade Federal de Pernambuco (UFPE), com um aumento de 432,67\%, e a UFPR, com aumento de $466,79 \%$.

Os resultados mostram que nos últimos dez anos (2004 - 2014), à medida que o número médio de docentes cresceu a uma taxa de 51,6\%, o número médio de discentes titulados cresceu a uma taxa menor, 43,6\%. Em 2004, as dez IES com maior representatividade em número de discentes titulados obtiveram uma média de 0,85 discente titulado para cada docente; em 2014 houve queda na média, foram 0,82 discentes titulados para cada docente. A redução do número de alunos titulados entre 2004 e 2014 foi de 3,61\%, revelando que em dez anos essas universidades tiveram um pior aproveitamento em relação à proporção de docentes vinculados aos programas e discentes titulados por ano.

A pós-graduação nacional formou, em 2014, um total de 68.575 mestres e doutores, um crescimento de $321 \%$ comparando-se a 1998. No geral, as dez IES com o maior número de discentes titulados representam $36,48 \%$ do total de mestres e doutores formados no Brasil. Somente a USP foi responsável por formar 9,35\% do total de discentes em 2014.

\section{IES com maior número de bolsas concedidas}

O número de IES que ofereceram bolsas de estudo em seus programas de pósgraduação, incluindo mestrado, mestrado profissional, doutorado e pós-doutorado, cresceu 254,29\% entre os anos de 1995 e 2014, conforme mostra o Gráfico 2.

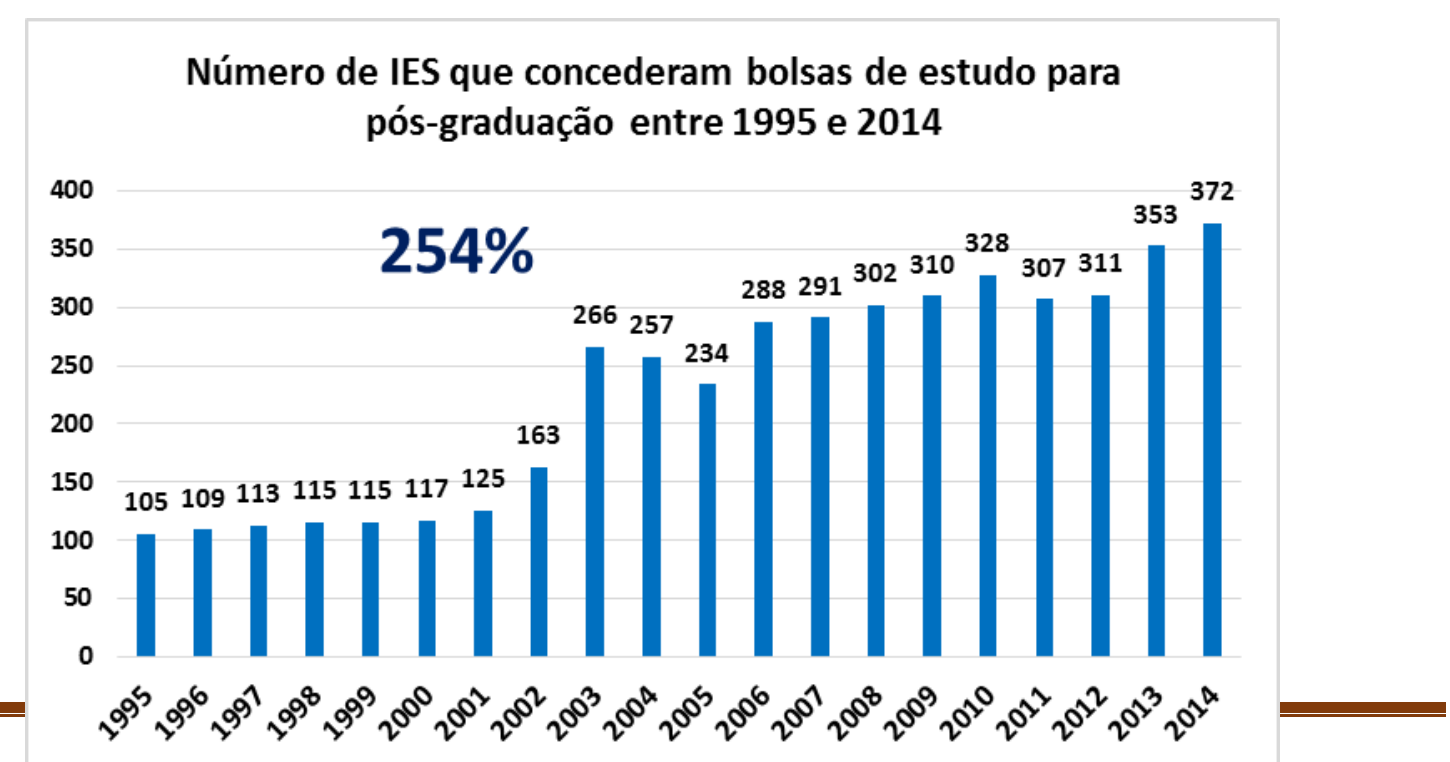

Revista de Administração Educacional, Recife, V. 1 . N 1 . 2017 jan./jun. 2017 p.20-37 
Gráfico 2- Número de IES que concederam bolsas de estuda na pós-graduação entre 1995 e 2014 Fonte: Geocapes (2016)

Em 1995 o país contava com 105 IES que ofereciam bolsas para pós-graduação, nos níveis de mestrado e doutorado. Os programas de mestrado profissional surgiram apenas em 1999, porém a concessão de bolsas para este nível só aconteceu a partir de 2011. Com relação as bolsas de pós-doutorado, essas só apareceram a partir do ano 2000.

Apesar da OCDE (2014) revelar que em 2011 os investimentos com estudantes brasileiros foram baixos, mesmo quando comparados a países com renda similar ao Brasil, como o México (US\$ 3.286), a Turquia (US\$ 3.240) e o Chile (US\$ 5.522), observa-se que somente entre 2002 e 2003 houve um crescimento de $63 \%$ no número de IES que receberam bolsas de estudo. Entre os anos de 2003 e 2014, evidenciou-se o incentivo financeiro à pósgraduação no país, tendo em vista o considerável aumento orçamentário disponível à Capes, e que aumentou a oferta de bolsas de estudo para mestrado e doutorado.

O Gráfico 3 mostra a distribuição regional das instituições que concederam bolsas no Brasil entre 1995 e 2014.

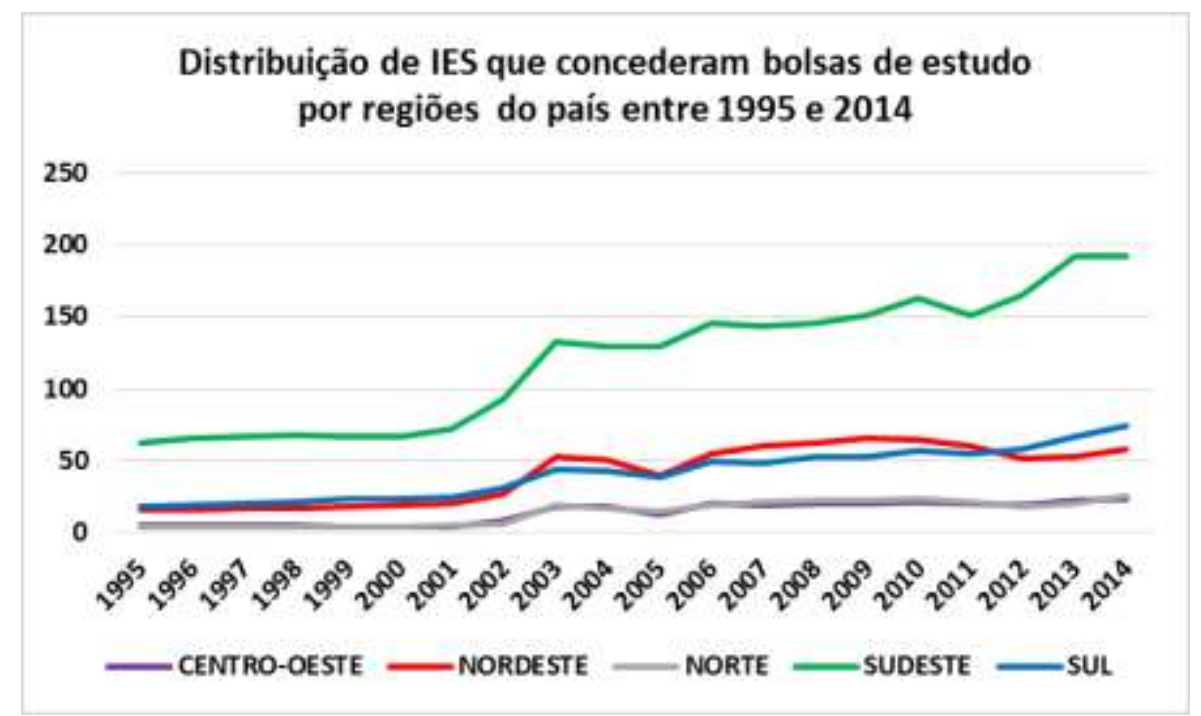

Gráfico 3 - Distribuição regional das IES que concederam bolsas de estudo entre 1995 e 2014 Fonte: Geocapes (2016)

Entre 1995 e 2014, a região Sudeste destaca-se com o maior número de IES que concederam bolsas de estudo, com 52,32\% do total de bolsas de estudo, mantendo proporção 
próxima ao número de programas de pós-graduação nacionais existentes na região Sudeste, que é de $46,59 \%$.

A região Nordeste representa $17,88 \%$ e o Sul representa $17,81 \%$ da distribuição de bolsas. Em números absolutos, o Nordeste fechou o ano de 2014 com 819 IES e o Sul, com 816 instituições que concederam bolsas para pós-graduação. Como comparação, em 2013, o Nordeste possuía uma fatia de $19,58 \%$ e o Sul 21,32\% do total de programas de pósgraduação, revelando um decréscimo na representatividade das duas regiões na distribuição de bolsas de pós-graduação.

O Centro-Oeste possui 8,16\% dos programas de pós-graduação no Brasil e 5,03\% ou 272 IES que concedem bolsas de estudo. Já o Norte, que possui apenas 4,96\% dos programas nacionais, possui $6,05 \%$ ou 277 IES que fornecem bolsas para pós-graduação.

Entre os anos de 1995 e 2014 houve um crescimento de 489\%, passando de 19.425 bolsas de estudo fornecidas por 87 IES para 94.985 bolsas em 2014, fornecidas por 343 IES. Dessas 343 instituições, foram analisadas as dez IES que forneceram o maior número de bolsas de estudo na pós-graduação, no período entre 1995 e 2014, conforme Gráfico 4.

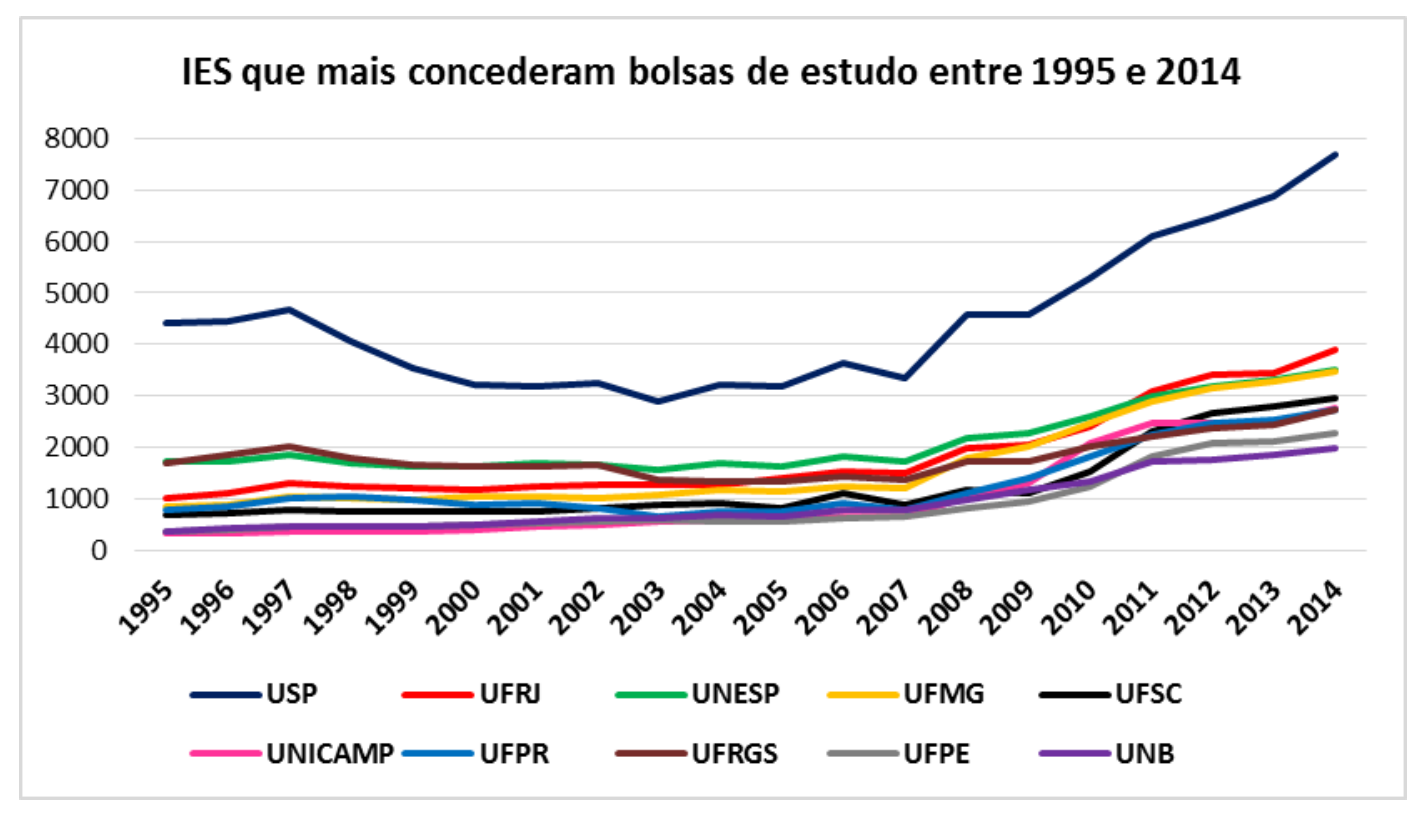

Gráfico 4 - IES que mais concederam bolsas de pós-graduação entre 1995 e 2014 Fonte: Geocapes (2016)

A USP representa $11,35 \%$ do total acumulado de bolsas concedidas (782.211) no Brasil entre 1995 e 2014. A UNESP manteve o segundo lugar com um total de 37.042 bolsas e 4,74\% do total de bolsas do país. A UFRJ vem em terceiro lugar com 5,40\%, seguido pela 
UFRGS com 4,22\%, UFMG com 3,26\%, UFPR com 2,68\%, UFSC com 3,28\%, Unicamp com $4,63 \%$, UNB com $2,34 \%$ e UFPE com $2,36 \%$ do total de bolsas no valor acumulado entre os anos analisados.

Entre 1995 e 2014, das dez IES que mais concederam bolsas de estudo para a pósgraduação, cinco são da região Sudeste, USP (SP), UFRJ (RJ), UNESP (SP), UNICAMP (SP) e UFMG (MG); três são da região Sul, UFRGS (RS), UFPR (PR) e UFSC (SC); uma é da região Nordeste, UFPE (PE); e uma é da região Centro-Oeste, UNB (DF); o que mostra concentração da distribuição de bolsas de estudo para pós-graduação nas regiões Sul e Sudeste do país. Isso é evidencia de que o direcionamento de recursos para bolsas de estudos na pós-graduação pode estar diretamente relacionado ao número de publicações científicas. No estudo apresentado por Almeida e Guimarães (2013), entre as dez instituições com mais publicações, entre 2000 e 2010, todas são das regiões Sul e Sudeste. A primeira instituição fora desses centros é a UFPE, na $11^{a}$ posição, e mesmo assim, com 72,3\% a menos de publicações do que a média das dez primeiras IES.

\section{CONCLUSÕES}

Nos quase 20 anos de pós-graduação analisados nesta pesquisa, denotam-se políticas e projetos que visam avanços da produção científica e tecnológica, assim como do crescimento da pós-graduação que é quase que inteiramente sustentado pelo trabalho das IES. A pósgraduação stricto sensu é apenas a ponta do iceberg de todo o cenário educacional e revela os méritos e deméritos das universidades brasileiras na corrida pelo crescimento científico nacional.

Observou-se o aumento significativo de todas as variáveis analisadas. Foi possível identificar quais IES mais contribuíram com o crescimento do sistema nacional de pósgraduação. A USP, a UNESP e a UFRJ foram as universidades com maior participação em número de programas, número de docentes, discentes titulados e concessão de bolsas de estudos.

Das dez IES que mais contribuíram com a pós-graduação nacional, todas são universidades públicas. Isso reforça o estudo de Souza (2015), quando cita que apesar da forte tendência de expansão do ensino superior privado no Brasil, são as instituições públicas as grandes responsáveis pelo desenvolvimento científico do país. O governo brasileiro precisa 
fomentar políticas que incentivem e promovam o crescimento dos programas de pósgraduação na rede privada de ensino superior.

Em relação ao número de programas, houve um aumento expressivo de quatro universidades, UNB, UFBA, UFPR e UFF, todas dobraram o número de programas de pósgraduação nos 17 anos estudados. O vínculo de docentes aos programas de pós-graduação também foi ampliado significativamente, com destaque para a UNB, a UFRN e a UFBA. As IES que apresentaram o maior crescimento no número de discentes titulados foram a UNB, a UFPE e a UFPR. Verifica-se que dentre as variáveis estudadas, as universidades com maior evolução foram a UNB e a UFBA.

O ponto frágil da pesquisa, por falta de detalhamento ou ampliação da amostra, referese à relação entre o número de programas e o número de docentes vinculados por programa de pós-graduação. Quando se observa a relevância científica que a USP e a UNICAMP representam no cenário nacional e a média de docentes por programa dessas instituições, que são relativamente altas, infere-se que a eficiência na produção científica está atrelada a quantidade de docentes vinculados por programa. Outro fator que poderia ser melhor detalhado em novas pesquisas é a relação entre discentes e docentes, buscando entender se um maior número de orientações por docente, ou seja, de alunos por docente titulado ao ano, prejudica ou melhora a qualidade da pesquisa científica, pode-se considerar como uma proporção favorável a média da USP, de apenas 0,8 discentes titulados por docente/ano.

O trabalho apurou uma breve contextualização da pós-graduação no Brasil e do papel que algumas IES apresentaram dentro desse contexto, ambos fundamentais para $o$ crescimento e a consolidação da pós-graduação brasileira. Como sugestão para futuras pesquisas, há a necessidade de estudos mais aprofundados relacionando alguns indicadores e ampliando o número de IES avaliadas, além de analisar cada variável por áreas do conhecimento, por exemplo.

Nas últimas décadas, o Brasil intensificou a adoção de políticas públicas que incentivam à produção de ciência e de tecnologia, assim como a abertura de novas universidades ou desenvolvimento de novos campus. Essa pesquisa confirmou que há um trabalho sendo realizado nas e através das IES em busca do crescimento e reconhecimento do sistema de pós-graduação nacional. Esses avanços, sustentados pelas universidades brasileiras, retratam o penoso caminho já trilhado por tal sistema em busca do reconhecimento mundial, o que em partes, já se sentiu com a conquista do $13^{\circ}$ lugar no ranking mundial de publicações científicas. 


\section{REFERÊNCIAS}

AFONSO, Mariângela da Rosa et al. Políticas de pós-graduação: um olhar sobre a expansão, qualidade e interdisciplinariedade. 2013. XIII Coloquio de Gestión Universitaria en Américas. Disponível em: < https://repositorio.ufsc.br/handle/123456789/114803 >. Acesso em 13 jun. 2016.

ALMEIDA, Elenara Chaves Edler; GUIMARÃES, Jorge Almeida. Brazil's growing production of scientific articles-how are we doing with review articles and other qualitative indicators? Scientometrics, v. 97, n. 2, p. 287-315, 2013.

BRASIL. Ministério da Educação. Coordenação de Aperfeiçoamento de Pessoal de Nível Superior. Plano Nacional de Pós-Graduação - PNPG 2011-2020 / Coordenação de Pessoal de Nível Superior. - Brasília, DF: CAPES, 2010.

BRASIL. Ministério da Educação. REUNI, 2015. Disponível em: < http://reuni.mec.gov.br/expansao >. Acesso em: 11 jun. 2016.

CIRANI, Claudia Brito Silva; CAMPANARIO, Milton Abreu; DA SILVA, Heloisa Helena Marques. A evolução do ensino da pós-graduação senso estrito no Brasil: análise exploratória e proposições para pesquisa. Avaliação: Revista da Avaliação da Educação Superior, v. 20, n. 1, p. 163-187, 2015.

CRUZ, Carlos Henrique de Brito; Beirão, Paulo Sérgio. Acadêmicos comentam relatório da ROYAL SOCIETY. Academia Brasileira de Ciências. Publicado em 30 de março 2011. Disponível em < http:??www.abc.org.br/article.php3?id article=1105>. Acesso em: 13 jun. 2016.

FIORINI, Joyce. Elaboração e análise de indicadores baseados em dados do sistema nacional de pós-graduação presentes nos cadernos de indicadores Capes, 2015. 2015. 127p. Dissertação de Mestrado (Mestrado em Ciência, Tecnologia e Sociedade) Universidade Federal de São Carlos. 2015.

GEOCAPES. Dados Estatísticos. Coordenação de Aperfeiçoamento de Pessoal de Nível SuperiorCAPES. Disponível em: http://geocapes.capes.gov.br/geocapes2/. Acesso em: 10 jun. de 2016.

GUIMARÃES, Jorge A. A pesquisa médica e biomédica no Brasil: comparações com o desempenho científico brasileiro e mundial. Ciência e saúde coletiva, v. 9, n. 2, p. 303-327, 2004.

IPEA, Instituto de Pesquisa Econômica Aplicada. Secretaria de Assuntos Estratégicos da Presidência da República. Comunicados do Ipea: Gastos com a Política Social: alavanca para o crescimento com distribuição de renda. Brasil, $\mathrm{n}^{\circ}$. 75, 2011. Disponível em <

http://www.ipea.gov.br/portal/index.php?option=com content\&id=7110.> Acesso em 10 de jun. 2016.

LEITE, Marcelo. Em 20 anos, país vai de $2^{\circ}$ a $\mathbf{1 3}^{\circ}$ em ranking de pesquisa. Folha de São Paulo, 2014. Disponível em: < http://www1.folha.uol.com.br/ciencia/2014/11/1541834-em-20-anos-pais-vaide-24-a-13-em-ranking-de-pesquisa.shtml >. Acesso em 06 jun. 2016.

MATTOS, Pedro Lincoln CL de. Nós e os índices: a propósito da pressão institucional por publicação. Revista de Administração de Empresas, v. 48, n. 2, p. 144-149, 2008.

MEIS, Leopoldo; ARRUDA, Ana Paula; GUIMARÃES, Jorge. The impact of science in Brazil. IUBMB Life, v. 59, n. 4-5, p. 227-234, 2007.

MOUSTAFA, Khaled. (2014). The disaster of the impact factor. Science and Engineering Ethics, doi:10.1007/s1 1948-014-9517-0. Disponível em < http://philpapers.org/rec/MOUTDO-2 >. Acesso em 14 jun. 2016.

OECD (2014), Education at a Glance 2014: OECD Indicators, OECD Publishing. Disponível em < http://dx.doi.org/10.1787/eag-2014-en>. Acesso em 10 de jun. 2016.

RANKING UNIVERSITÁRIO FOLHA. Apresentação. Ranking Universitário Folha. 2015.

Disponível em: http://ruf.folha.uol.com.br/2015. Acesso em: 22 abr. 2016. 
SOUZA, Pedro Bastos de. Brasil do ano 2000 revisitado: desafios em inovação tecnológica e o papel da universidade. Revista Brasileira de Pós-Graduação - RBPG, Brasília, v.12, n. 28, p. 415 439, 2015. 